\title{
Responses of cellular adhesion strength and stiffness to fluid shear stress during tumor cell rolling motion
}

Weiwei Li, ,t Sifeng Mao, $;$ Mashooq Khan, Qiang Zhang, Qiushi Huang, Shuo Feng, and Jin-Ming Lin*

Department of Chemistry, Beijing Key Laboratory of Microanalytical Methods and Instrumentation, MOE Key Laboratory of Bioorganic Phosphorus Chemistry \& Chemical Biology, Tsinghua University, Beijing 100084, China.

$t$ These authors contributed equally to this work.

*Corresponding author. Email: jmlin@mail.tsinghua.edu.cn

\section{Content}

Figure S1

Figure S2

Figure S3

Figure S4

Supplementary movie S1, S2, S3, S4, S5 


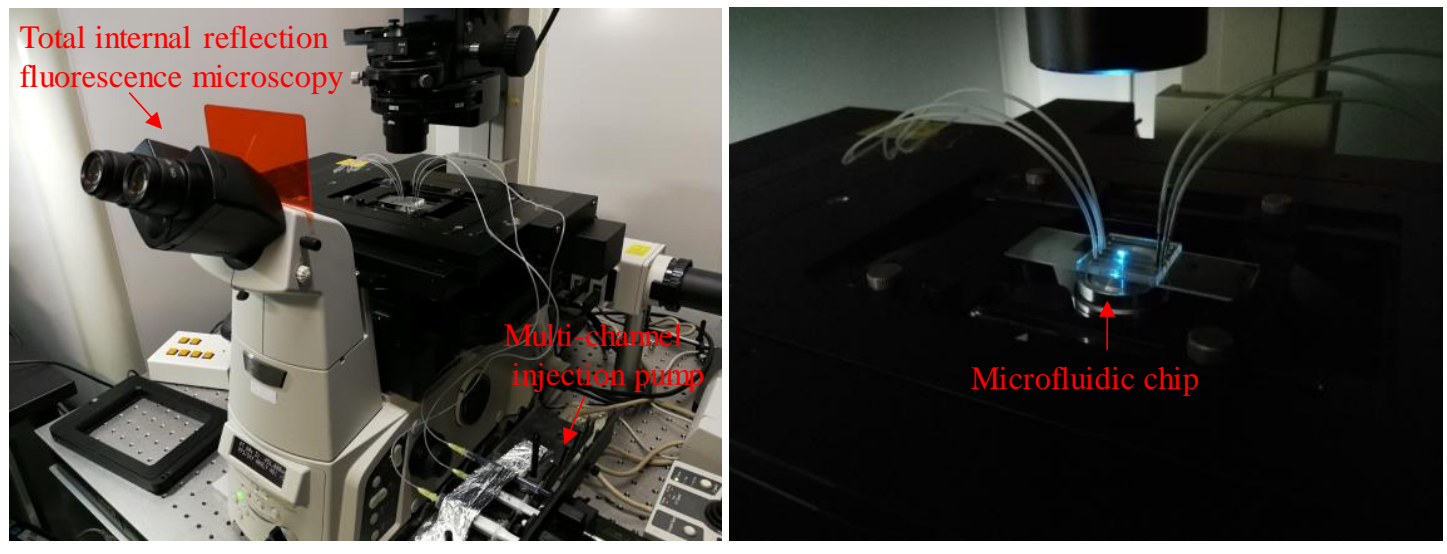

Figure S1. The microfluidic platform for cell flow culture, fluid shear stress stimulation and realtime imaging.

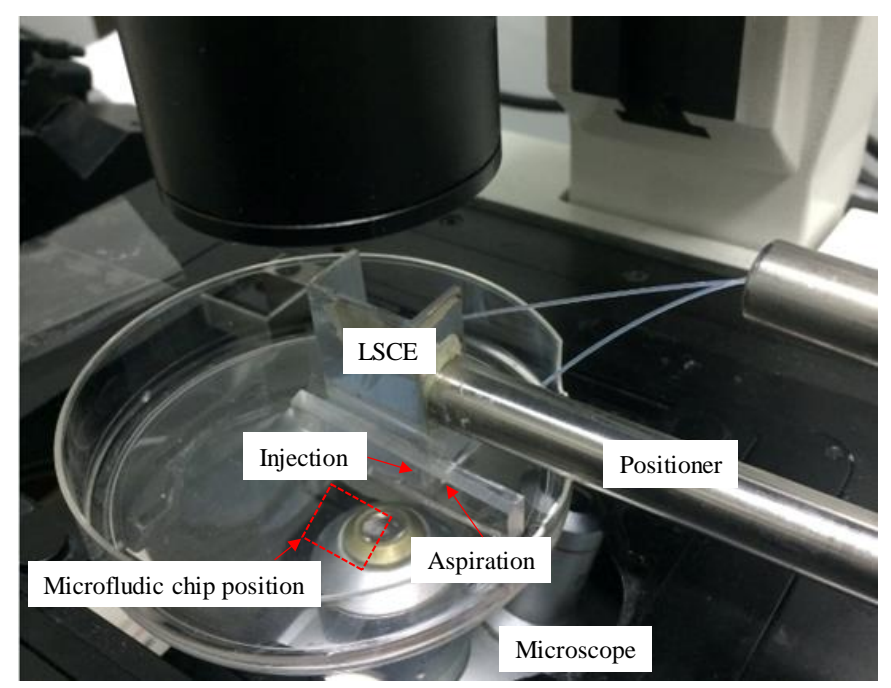

Figure S2. The setup of live single-cell extractor (LSCE) for in situ intact cell detachment. 

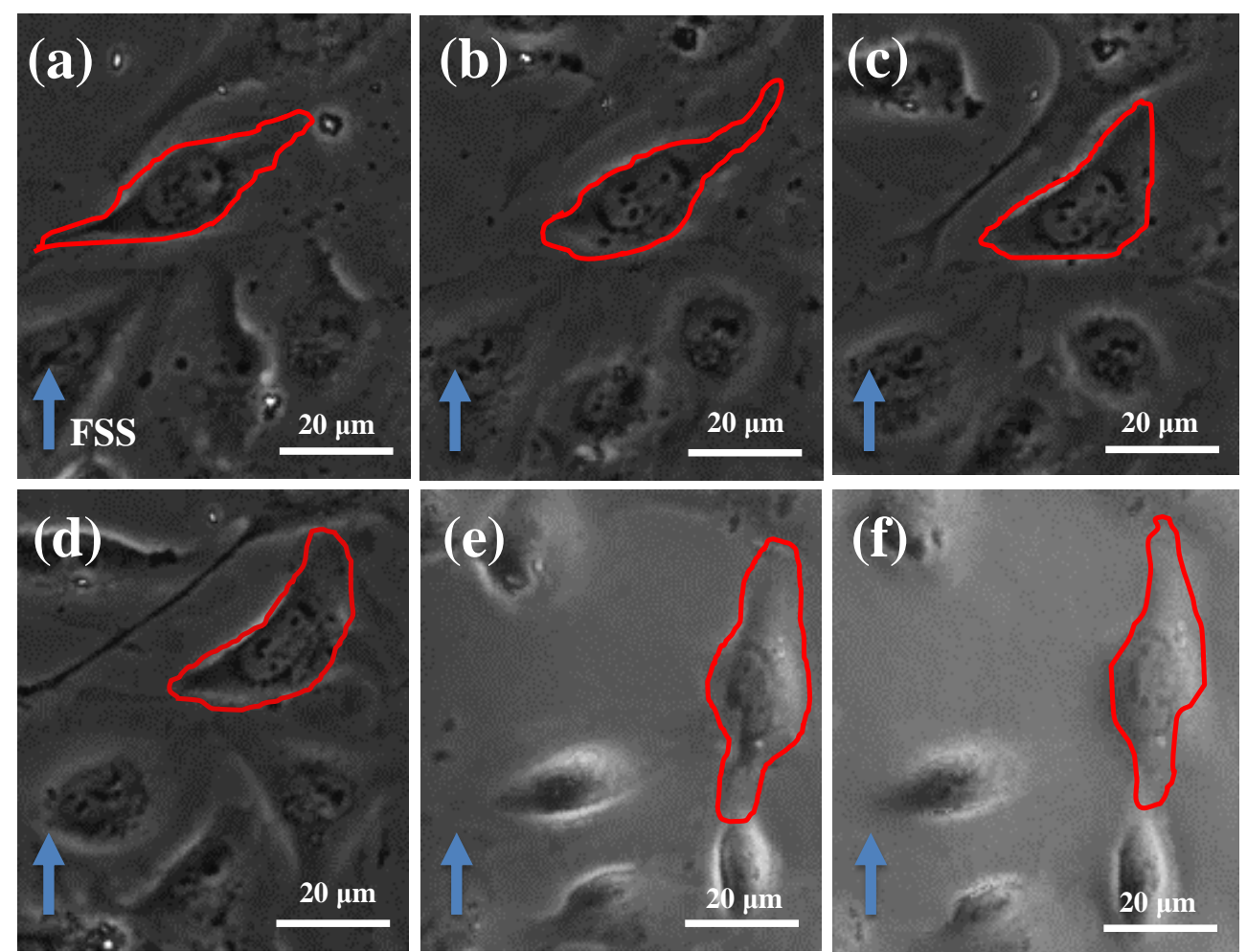

Figure S3. HUVEC cells change the direction of alignment with the fluid direction (form a to f) at the flow rate of $10 \mu \mathrm{L} / \mathrm{min}$.

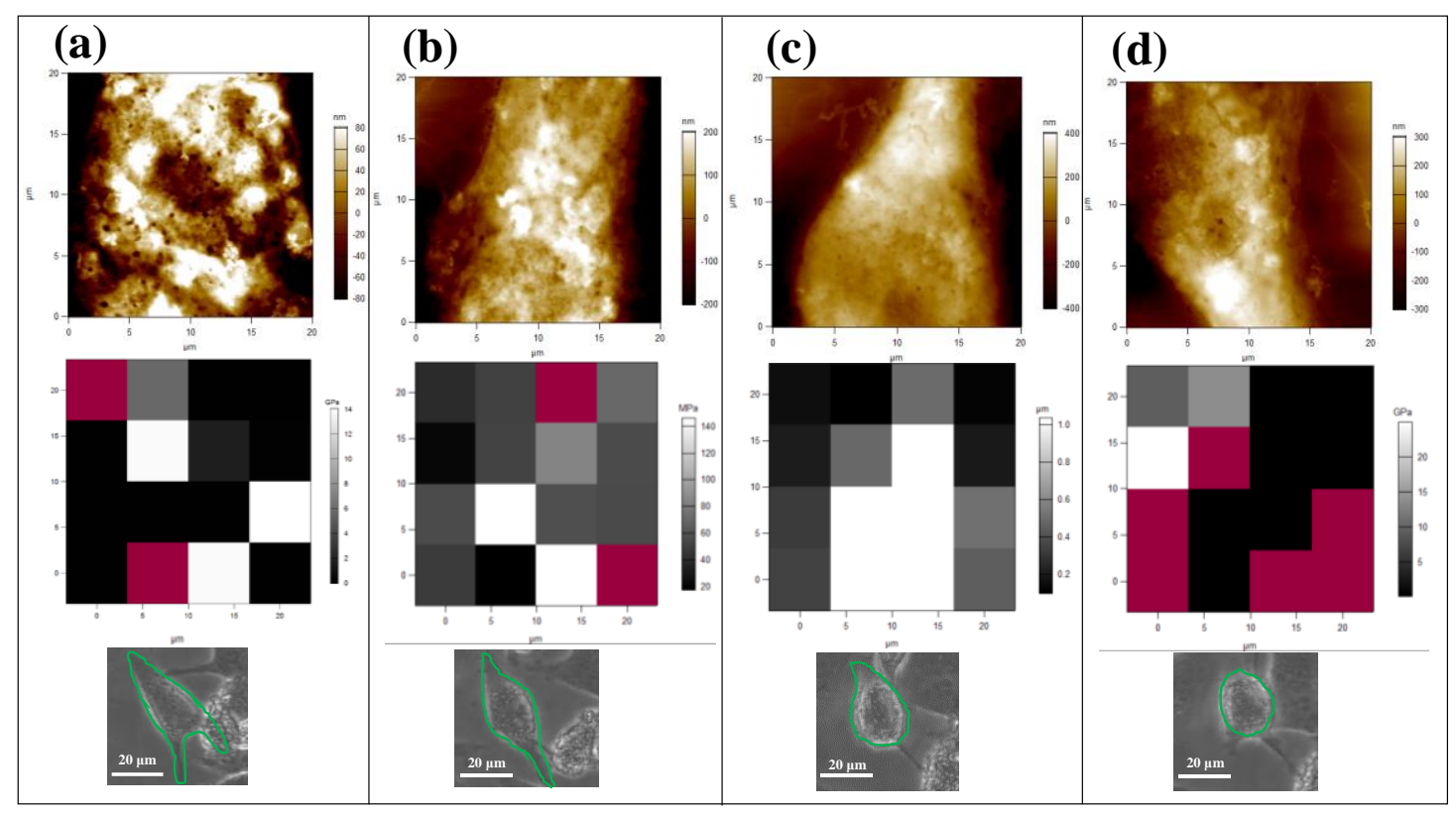

Figure S4. Scanning map of U87 cells by AFM and the Young's modulus of U87 cells with different cell morphologies (a) concave shape (b) elongated shape (c) less elongated shape (d) round shape. 
Movie S1. The process of in situ intact cell detachment by LSCE to measure cell adhesion strength.

Movie S2. Real-time imaging of U87 cell's rolling motion at the flow rate of $10 \mu \mathrm{L} / \mathrm{min}$.

Movie S3. Cells rolling motion of labeled U87 at the flow rate of $1 \mu \mathrm{L} / \mathrm{min}$.

Movie S4. Cells rolling motion of labeled U87 at the flow rate $10 \mu \mathrm{L} / \mathrm{min}$.

Movie S5. Cells rolling motion of labeled U87 at the flow rate of $15 \mu \mathrm{L} / \mathrm{min}$. 